contribution to the streams and rivers by means of springs and seepages from the underground stores built up by percolation, and it was emphasised that in cases during the past drought where reservoirs or lakes utilised for public supply were maintained at a fair level, this was owing entirely to underground water which issued steadily as feeders for the impounded supply. The relative proportions of evaporation, run-off and percolation vary greatly in different localities and seasons, so that general formulæ applicable to any district cannot be used with safety. Evaporation may be $\mathbf{5 0}$ per cent of the rainfall ; run-off up to 92 per cent and percolation 80 per cent or even $90-95$ per cent.

The properties of rocks in regard to absorption and transmission of water were discussed by $\mathrm{Dr}$. Smith, who pointed out the distinction between porosity and perviousness, stating in regard to the former that 30-40 per cent of the volume of a mass of loose sand and gravel is represented by pore-space, whilst that of naturally cemented sands and gravels is only half that amount. On the average, igneous rocks have a pore space of 1 per cent, shale has 4 per cent and limestones have an average of about 5 per cent. On the other hand, the porosity of chalk attains a maximum of about 50 per cent. Pore spaces vary in size from the microscopic (micropores) to those visible to the naked eye (macropores), and the relative proportions of these to the total porosity of a rock determine to a large extent its perviousness (apart from fissures).

The perviousness of a rock is its capacity to allow water to pass through it, and depends not entirely upon the porosity (total volume of pore space), but rather on the size of the pore spaces and their continuity or interconnexion one with another. In most districts, the rocks are saturated below a depth dependent upon several factors-porosity, amount of rainfall and surface profile. In permeable rock, the surface of the saturated zone is termed the 'water table' and the water below it 'ground water'. Above the water table, in the sometimes-called 'zone of aeration', is 'wandering' or 'vadose' water. Water tables are fairly easy to determine in the comparatively unaltered stratified rocks, but not so easy in the impervious, or relatively impervious rocks, exemplified by the more ancient strata and by igneous rocks.
While in granitic areas large supplies are best sought from streams, yet many smaller supplies are to be found underground, due to the water held in the joints. This is particularly the case in Cornwall and Devon. As a class, however, granitic and kindred rocks are not good aquifers, and, in his second lecture, Dr. Smith discussed the Upper Palæozoic, Mesozoic and Tertiary strata, in which underground water occurs in large quantities. The fluctuation of the water table and the breaking out of bournes were described, with instances in the chalk uplands and elsewhere, and reference was made to the researches of Baldwin Latham and others.

Artesian wells and basins received explanatory notice, and it was pointed out that some artesian wells are very deep, having been bored to $4,000 \mathrm{ft}$. in Berlin and in St. Louis and Pittsburgh. These are deeper than any in Great Britain, most of which range at various depths up to $1,000 \mathrm{ft}$., with specially deep cases at Ottershaw (1,585 ft.), Virginia Water $(1,430 \mathrm{ft}$.$) and Boultham, Lincoln (1,562 \mathrm{ft}$.$) . The$ exhaustion of artesian wells may be brought about by over-pumping of the natural reservoir, clogging of the rock pores, unsatisfactory casing and heavy pumping from neighbouring wells. Of the pervious, or partly pervious, formations of Great Britain, the Carboniferous, Millstone Grit and Coal Measures; the Triassic sandstones, the Inferior and Great Oolites, the Lower and Upper. Greensands and the Chalk may be regarded as the chief water-bearing strata.

In the final lecture, the geological complications (faults, flexures, cover) affecting the circulation of underground water were considered, the variation in thickness of strata and missing formations. The best way of studying the question of thickness is to draw 'isopachytes' or 'lines of equal thickness'. This information, together with surface contours related to Ordnance datum, should prove of great utility. Another point of interest to hydro-geologists and water engineers is the change in the quality of water beneath cover, from that of water at the outcrop. Most waters, where traced down an artesian slope, or into an artesian basin, are found to change in mineral character, sometimes quite rapidly.

Dr. Smith concluded his review by remarking that the question of locating supplies is often a complex matter, demanding considerable knowledge from the hydro-geologist and skill from the water engineer.

\title{
Recent Developments in Luminous Discharge Tubes
}

$I^{N}$ the Electrician of January 31, Mr. C. C. Paterson gives an interesting account of recent developments in luminous discharge tubes. There are two directions in which developments are making rapid progress. The first is the use of 'super pressure' lamps, and the second is the use of luminescent powders.

The high-pressure mercury vapour lamp which runs at a pressure of 150 atmospheres is a very courageous step in advance, but it is not yet known whether it will prove suitable for practical use. In the ordinary mercury vapour lamp, the vapour is under a pressure of two atmospheres; the huminous column does not fill the tube, but contracts into a 'rope' stretched along its axis, and most of the power is being expended inside this. As the vapour pressure increases, the total volume of the luminous vapour diminishes, and as the power is concentrated in this, the ionisation becomes extremely intense and the intrinsic brilliancy greatly increases.

The possibility of the usefulness of luminescent powders has now been demonstrated in the case of cold cathode (high voltage) tubes, and doubtless they will soon be applied to hot cathode tubes. Luminescent powders have been used for some years, but research has now shown methods of greatly enhancing their brilliancy. Mercury vapour has marked radiation in the ultra-violet, and when it falls on a suitable luminescent material its wave-length becomes longer and the radiation becomes visible. Zinc and cadmium sulphides are well known to be luminescent, but there 
are many other substances, and so research in this direction is most promising.

Mr. Paterson has experimented with a 'sign type' tube which without luminescent powder gave 20 candles (250 lumens) with an efficiency of about four tenths of a candle per watt. With the inside surface coated with one of the new powders and using the same electric power, it gave 240 candles, the efficiency being increased twelve times.

One of the attractive features of luminescent powders is the 'band' nature of their spectra. As a rule, ordinary luminous discharge tubes emit line spectra at a definite number of single and isolated wave-lengths; the powders under suitable stimulation emit over a group of wave-lengths. They are thus very suitable for filling in gaps in the spectra of the light given out by vapours and gases.

Another type of lamp developed last year uses a tungsten filament in series with, and in the same transparent envelope as, a high-pressure mercury discharge tube. This serves the double purpose of eliminating part of the regulating device and introducing much needed red radiation into the light coming from the mercury vapour. The efficiency is of the order of two candles per watt, and the combination will be a competitor to the tungsten lamp for the interior lighting of factories.

\section{Electrically Produced Music}

$\mathrm{T}$ HE paper read before the Royal Society of Arts on March 4 by Mr. G. G. Blake on electrically produced music considered only those instruments which depend on the method known in radio as the 'heterodyne'. Mr. Blake showed first the production of beat notes by two musical instruments. When they were both vibrating at the same frequency they emitted the same note. By gradually altering the frequency of one of the instruments, a third - the heterodynenote could be heard. As the instruments went more out of tune, the frequency of the beat note became higher. This showed the heterodyning of sound waves.

When radio waves produce a heterodyne note at very high frequencies, each of the individual notes is inaudible, but the beat note takes place just as with low-frequency sound waves and is clearly audible. Mr. Blake, using a special instrument which he calls the ethonium, showed the following phenomena. The instrument consisted merely of two electrical transmitters suitably coupled to a wireless set. With the two transmitters and the wireless set in tune, nothing could be heard. When one of the transmitters was slightly detuned, beat notes were emitted from the loud speaker of the set. Movement of the hand towards or away from the aerial attached to one of the transmitters varied the frequency of that transmitter and the musical notes produced varied from deep bass to the shrillest treble. The alteration of note is due to very minute changes in the electrostatic capacity of the aerial. The slightest movement of the hand at a distance of a yard from the aerial alters the pitch of the note.

The circuits of the ethonium were then readjusted and the existence of a zone about two feet from the aerial was demonstrated where the presence of the hand produced no effect. Moving the hand from this zone to or from the aerial produced a deep bass note, increasing in pitch the farther the hand was moved away from the zero zone. Moving the hand away from the aerial diminishes its capacitance. Mr. Blake showed how the zero zone could be moved farther away from or nearer to the aerial.

In working the instrument, the control of this zero zone is of importance. It gives the player the ability to extend or contract the length of the musical scale over which he intends to play. It can be compared to a piano with an elastic keyboard which can be extended so as to make it suitable for a man with long arms, or contracted to suit a player with a short reach.
A demonstration was given of the superposing of music played by the ethonium upon radio-gramophone music. By connecting the electro-magnetic pick-up from a gramophone to the grid circuit of the first amplifying valve of the wireless set, the amplifier also being connected to the detector circuits, a musician can play any music he desires on the ethonium, to a suitable radio-gramophone accompaniment, his music and that of the gramophone being produced simul. taneously from the loud speaker of the wireless set.

It has been shown previously by Theremin and others that unwanted harmonics can be easily suppressed by suitable filter circuits and needful over. tones can be introduced. Thus the quality of electrically produced music can be altered so that it gives a faithful imitation of a flute, a violin, a cornet, a banjo and other musical instruments.

An important fact demonstrated by Mr. Blake was that the production of musical notes by heterodyne is independent of the fundamental frequency of the transmitters employed. Provided the two transmitters are exactly in phase initially, they can be operated at any desired frequency. One of the ethoniums shown operated at $1 \cdot 25$ million cycles. When one of its transmitters is detuned it is only oscillating at $1 \cdot 2499$ million cycles, the difference of frequency between the transmitters being 100 cycles, which is within the audible range. Another of the ethoniums shown operated at a frequency of $0 \cdot 67$ million cycles ; if one of the transmitters be detuned to a frequency of $0 \cdot 669,900$ the difference between them will be again 100 cycles, and the second ethonium emits exactly the same note as the first. When both the ethoniums sound simultaneously, no wireless interference takes place between them. This opens up the possibility of electrically produced orchestral music from a number of these or similar electrical instruments when played simultaneously.

Many instructive lecture experiments were shown. With the ethonium tuned to silence, it was demonstrated that almost any object placed on the top of the aerial increased its capacitance so that it produced a note. The notes produced by a pin, a coin, a lump of sugar, an onion, etc., were easily heard and distinguished. Placing a piece of cardboard, a sheet of glass, a large suitcase, a wooden drawingboard or a metal tea-tray between the hand of the player and the aerial did not interfere with the use of the instrument; but when the object was metallic, it was essential that it be insulated from the earth. 